\title{
A Review of Additive Manufacturing in Aerospace Application
}

\author{
Meena Pant, Pritam Pidge, Leeladhhar Nagdeve, Harish Kumar* \\ Department of Mechanical Engineering, National Institute of Technology Delhi, Delhi 110 040, India
}

Corresponding Author Email: harishkumar@ nitdelhi.ac.in

https://doi.org/10.18280/rcma.310206

Received: 3 September 2020

Accepted: 17 December 2020

\section{Keywords:}

additive manufacturing, aerospace industry, lightweight component

\begin{abstract}
In the era of Digital Manufacturing and supporting state-of-the-art, i.e. Additive manufacturing (AM) technology is getting more popular known as 3D printing, AM has created its own space in the fastest growing industry. 3D printing has evolved in previous years, and now, it is being used in several social life domains. The main application of this process has found in prototyping, aerospace industry, biomedical and dental implants. Additive manufacturing prints a part in a layer by layer or line by line pattern. It opposes the basic concept of traditional manufacturing. Advances in composite and multi-material manufacturing provide new opportunities for the convenient manufacture of lightweight parts and modern products, such as flapping wings, satellite brackets, and lightweight components for the aviation industry. It is a particular technology that varies from conventional and subtractive development in terms of lightweight, enhanced features, lower fuel consumption, and optimized machine performance, so on. This paper addressed the progress of AM in the aerospace field and addressed the issues of AM linked to a specific aerospace component.
\end{abstract}

\section{INTRODUCTION}

Direct digital manufacturing is a production methodology that essentially consists of creating net practical parts from the product design to be produced. Since additive manufacturing processes (AM) require a limited source of energy. It can print complex parts so; this technique is suitable for automobile, aerospace, biomedical, and other industrial application [1]. $\mathrm{AM}$ is a material joining process in which material either in powder, sheet, and wire/filament form used to stack the layer together to produce three dimensional (3D) component which opposes the subtractive manufacturing process. Direct transformation of raw materials into complicated 3D shapes focused on digital data produced by slicing and rasterizing computer-aided design (CAD) file enables substantial time and expense savings, where technology is appropriate for manufacturing end-use parts [2]. American society of testing and materials (ASTM) F-42 committee [3] has classified the $\mathrm{AM}$ process into seven categories (shown in Table 1) which are as follows: extrusion-based, photopolymerization based, direct energy deposition (laser cladding), powder bed fusion, material jetting (polyjet), sheet lamination (sheet forming) and binder jetting. Different AM technology covers a range of main parameters related to output response. The role of these parameters is essential for the final assessment of quality parts. Common metal AM types are direct energy deposition [4], which includes laser engineering net shape (LENS) and free form electron beam manufacturing [5], and powder bed fusion include selective laser melting and electron beam melting [6, 7]. The popular available AM technologies are stereolithography, multijet modeling, fused filament fabrication (FFF) [8], and three-dimensional printing (3DP) for nonmetallic components such as plastics, and composite materials, and ceramics. All metal and non-metal parts produced using AM technology have potential applications in the aerospace industry. Direct metal laser sintering, selective laser melting, laser curing, and laser metal deposition are the most used technologies for aerospace applications. A suitable selection of process parameters is essential for a product that depends on the requirements and end-use criteria [9]. The main applications of AM in the manufacturing industry include rapid prototyping, direct component development, rapid tooling, and reconstruction of metal component $[10,11]$. The evolution of AM minimizes the issue of inventory and shortens the supply chain. The aerospace industry required high-quality components which are often complex and time-consuming. Although, the conventional manufacturing process is insufficient for small-scale production because there is a lot of wastage of material during the machining process and making complex structures for the aerospace application takes several months. The definition has changed after the restructuring of the manufacturing sector.

Various industries adopted AM technology for making prototypes. In 2017, nineteen percent of the AM market compromised by aerospace industry. Research and Markets recently published a study in terms of AM is a disruptive technology for the aerospace industry and they announce the possible growth rate of $23.01 \%$ between 2017 and 2021 [12]. In the aerospace industry, lightweight and fuel consumption are the basic parameters which are the concern of the industry. The aerospace components are directly exposed to hightemperature environments, AM has the ability to handle higher temperatures materials that are hard to cast, such as nickel alloys and inter-metallic materials through conventional manufacturing. 
Table 1. Seven categories of additive manufacturing process [13]

\begin{tabular}{|c|c|c|c|c|}
\hline Techniques & $\begin{array}{c}\text { Staring phase of } \\
\text { material }\end{array}$ & Strength of work & Weaknesses & Companies \\
\hline $\begin{array}{l}\text { Stereolithography } \\
\text { (SLA) }\end{array}$ & $\begin{array}{l}\text { Photo polymerization } \\
\text { (liquid-based system) }\end{array}$ & $\begin{array}{l}\text { Quick printing speed } \\
\text { High resolution }\end{array}$ & $\begin{array}{l}\text { Changing the resin is } \\
\text { difficult to handle } \\
\text { Machine set up larger than } \\
\text { resin needed. }\end{array}$ & $\begin{array}{c}\text { 3D Systems (US), } \\
\text { Envision Tec } \\
\text { (Germany) } \\
\text { Object }\end{array}$ \\
\hline $\begin{array}{l}\text { Powder bed fusion } \\
\text { (PBF) }\end{array}$ & $\begin{array}{l}\text { Powder based system } \\
\text { uses plastic, ceramic } \\
\text { and composites metal } \\
\text { in the powder form }\end{array}$ & $\begin{array}{c}\text { High strength } \\
\text { moderate stiffness } \\
\text { Good chemical resistance }\end{array}$ & $\begin{array}{l}\text { Surface quality is porous } \\
\text { nature } \\
\text { High costs, slow process }\end{array}$ & $\begin{array}{l}\text { 3D systems, EOS } \\
\text { Blueprint, SLM } \\
\text { solutions } \\
\text { Renishaw }\end{array}$ \\
\hline $\begin{array}{l}\text { Fused filament } \\
\text { fabrication (FFF) }\end{array}$ & Solid based system, & $\begin{array}{c}\text { Easy to handle } \\
\text { User friendly, Prototyping }\end{array}$ & $\begin{array}{l}\text { Poor surface finishing } \\
\text { Difficult to handle } \\
\text { extruder part }\end{array}$ & $\begin{array}{l}\text { Stratasys } \\
\text { Voxel jet }\end{array}$ \\
\hline $\begin{array}{c}\text { Laminated object } \\
\text { manufacturing (LOM) }\end{array}$ & $\begin{array}{c}\text { Solid based adhesive } \\
\text { bonding between } \\
\text { materials }\end{array}$ & $\begin{array}{l}\text { Reduce manufacturing lead } \\
\text { time } \\
\text { Good process for larger } \\
\text { structure }\end{array}$ & $\begin{array}{l}\text { Constraint to complex } \\
\text { structure } \\
\text { Poor surface quality }\end{array}$ & $\begin{array}{l}\text { Mcor technology, } \\
\text { SD } 300 \text { printer, } \\
\text { Fabrisonic (US), } \\
\text { Mcor (Ireland) }\end{array}$ \\
\hline Binder jetting & Liquid based process & $\begin{array}{l}\text { Applicable for complex } \\
\text { ceramic structure } \\
\text { Fast and flexible method for } \\
\text { complex structure }\end{array}$ & $\begin{array}{l}\text { Poor adhesion between } \\
\text { layers } \\
\text { Fine resolution difficult to } \\
\text { achieve }\end{array}$ & $\begin{array}{c}\text { 3D systems Ex } \\
\text { One (US), } \\
\text { Voxeljet } \\
\text { (Germany) } \\
\text { Stratasys }\end{array}$ \\
\hline $\begin{array}{c}\text { Direct energy } \\
\text { deposition (DED) }\end{array}$ & $\begin{array}{l}\text { Metal and its element } \\
\text { used in powder form }\end{array}$ & $\begin{array}{l}\text { Minimize manufacturing cost } \\
\text { and time, } \\
\text { Useful for printing of large } \\
\text { component }\end{array}$ & $\begin{array}{c}\text { Require a dense support } \\
\text { structure } \\
\text { Low surface quality }\end{array}$ & $\begin{array}{l}\text { Optomec (US), } \\
\text { POM (US }\end{array}$ \\
\hline Multi jet printing & Multi jet fusion & Full-color objects printing & $\begin{array}{c}\text { High porosities in finished } \\
\text { part }\end{array}$ & 3D systems \\
\hline
\end{tabular}

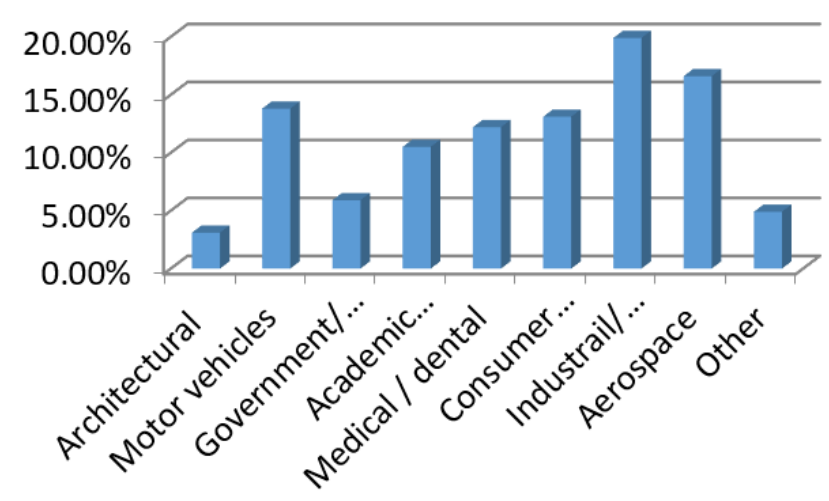

Figure 1. Wohler's Worldwide Report on the AM industry's in 2016 [14]

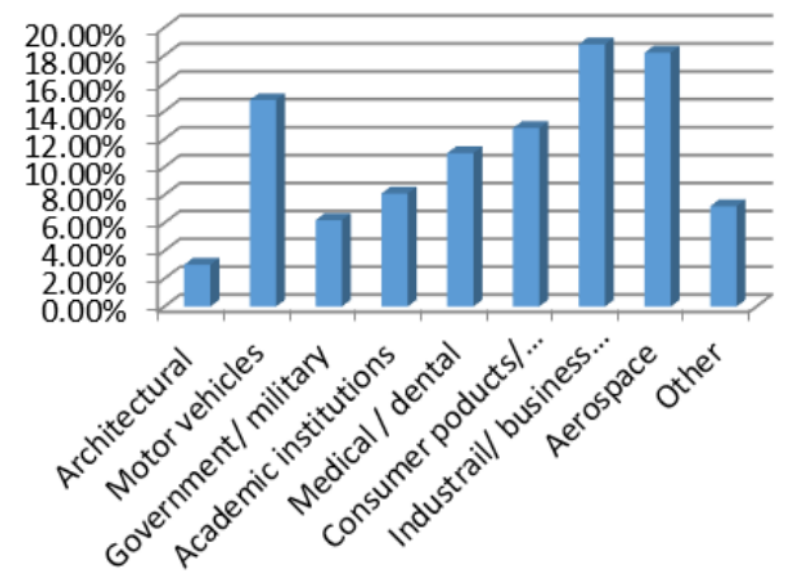

Figure 2. Wohler's Worldwide Report on the AM industry's in 2017 [14]
The incorporation of Wholer's association has been widely recognized as the leading consulting firm and the most prominent expert for AM in the world. Figure 1 and 2 shows the progress of AM industry in various fields from 2016 to 2017. The present study reports the current status of AM in the aerospace industry and discusses the limitation of AM.

\section{PRESENT STATUS OF AM IN AEROSPACE INDUSTRY}

Rapid developments in AM technology in the last few years have led to the proliferation of technology and the application of such useful technology in the aerospace industry. Additive Manufacturing was earlier a niche participant in the aerospace industry for manufacturing the prototype of parts. However, in recent developments of AM techniques have quickly become a tactical technology that produces revenue around the supply chain for the aerospace industry. In the aerospace industry, companies are started already using dedicated systems to manufacture parts via transforming AM's strategic dynamics include Boeing, Airbus, Lockheed Martin, Honeywell, and Pratt \& Whitney, Hindustan Aeronautics Limited (HAL), General Electric (GE). Some of the recent examples are addressed as follows:

Airbus is investigating ninety different cases in which the $\mathrm{AM}$ is used to operate aircraft of the next generation. In June 2014, Airbus Company developed a titanium bracket for an aircraft application. The first titanium bracket was made by the SLM process with bionic design and installed in Airbus A350 XWB [15]. Since it was a successful test, and it leads to a manufacturing agenda for a company. 3D printing can save up to thousands of dollars by minimizing fuel consumption due to reduced weight. We know that every kilogram weight reduction can prevent $25 \%$ of $\mathrm{CO}_{2}$ emissions. Decarburization is the main problem in the parts which are manufactured by 
the conventional process so that these companies using AM technique to manufacture the part for aircraft applications. One of the most interesting facts of this technology is that it can be designed virtually on the modeling software, manufactured at the site, and tested within fewer periods. Now Airbus made small-scaled pilotless aircraft using this technology named THOR [16]. They installed the first 3D printed part in the commercial aircraft. Airbus engineers in its division of Defence and Space faced two major obstacles concerning to bracket construction. The first challenge is that brackets must securely connect the part and second is that it can withstand at a high temperature outside the earth's atmosphere. This difficulty is overcome by fabricating the bracket through the 3D printing process [17].

General Electric (GE) Aviation uses the Powder Bed Fusion system to manufacture the next level of complex jet engine parts using an EOS 3D metal printer. Jet engine nozzle manufactured by Direct Laser melting process. They said that this part is up to 25 percent lighter and more complex than its predecessors and incorporates many assembled components in the past into one part [18, 19]. GE's executive team had seen the ability of AM and fundamentally changed how GE aviation operates. Huge investments were made in GE's aviation business unit to improve 3D printing technology. GE Company improves the total capability of industry and has expressed a desire to print more than $100 \mathrm{k}$ pieces by 2020 . 3D printing technology has gone from producing a small prototype to large industrial parts for industries, such as the titanium is used to $3 \mathrm{D}$ print the domes in onboard orbital satellites by Lockheed Martin [20]. It is an aerospace and defence corporation, highlighted its 5Ps (a proposal, production support, prototype, procurement\& production) AM model to show the promise of a traditional U.S. lifecycle. Airbus, with multinational safety and aerospace corporation Lockheed Martin, has signed an AM deal. To increase production with such emerging technology and to minimize overall costs, the partners will collaborate to find parts of the F-35 Lightning II aircraft. The part count was minimized by making assemblies directly. This company is using this technology to design 3D printed door handles, cup handles, dome prototypes for aircraft, and toilet seats in military aircraft It is giving innovative solutions for complex manufacturing processes with ease [21]. They also manufacture a 3D printed fuel tank with the use of AM. They are also developing the giant 3D printed titanium parts for aircraft. Boeing makes a choice using 3D Printing technologies. 300 Manufacturing parts for aircraft application made using 3D printing technology, with 10 separate aircraft manufacturing programs. At current, more than 20,000 produced pieces with nonmetallic additives, it is expected to be enhanced more parts for the aircraft application [22].

Pratt and Whitney [23] create Aero Engine components using 3D printing technology. Pratt and Whitney have supplied their first engine for the C-Series passenger aircraft to the world's largest aircraft maker, Bombardier. Using this technology significantly reduced manufacturing time and complexity. From concept designs to prototype and then convert into the final product using 3D printing technology reduces wastage and raw material usage. It also helps in the precise production of components with intricate geometry with decreased tooling and enables the manufacture of different parts from an assembly in an integrated unit. Rolls-Royce [24] aims to examine the more amount of the front bearing housing for engines. The complex shape and wide front bearing titanium component with a diameter of $1.5 \mathrm{~m}$ and a thickness of $0.5 \mathrm{~m}$, carrying 48 aerofoils, were fabricated using the AM Electron Beam Melting technique. Using this technology, Rolls-Royce saved production time about 30 percent compared to traditional methods of production.

The Agnikul COSMOS [25] Company incubated at IIT Madras started using 3D printing technology to build a smallsized semi-cryogenic rocket of a range of 20 kilos Newton that can hurl satellites of weight up to $100 \mathrm{~kg}$ in earth lower orbit. They designed it and planned to make with additive manufacturing. As per the demand from customers for smallsized satellites, they are going to 3D print the engine and send them to space. The Team INDUS, they are looking to send a rover to the moon. It has $3 \mathrm{D}$ printed wheels bringing down the cost of the time to build it and also lowering down the cost. This technology is proving itself very much promising in aerospace applications [26]. Indian Space Research Organization (ISRO) already started using 3D printing technology for 3D printed components for its spacecraft. The feed cluster component is 3D printed for GSAT-19 by its client to send it into space three years ago. Wipro 3D is a client of ISRO who gives them 3D printed components for aircraft [27]. They are printed the specific parts by 3D printing. These specific parts include the thrusters for the satellite engine. As understanding the importance of $\mathrm{AM}$ in part consolidation they started using $3 \mathrm{D}$ printing. It needs $7-8$ years to mature this technology to use in fully printed for aircraft application. ISRO has built its 3D printing manufacturing system to produce small aircraft parts. Hindustan Aeronautics Limited (HAL) has started using 3D printing to make a part for $25 \mathrm{~kg}$ small engine as its component. They are also working on the unmanned aerial vehicle to produce its parts with $3 \mathrm{D}$ printing technology. Hindustan Aeronautics Ltd. (HAL) is India's only manufacturer of armed military aircraft. They are making decisive steps in making "Made in India" a globe-class name by entering into additive manufacturing [28]. They used AM technology to set a reference model of an aircraft engine that wages around $25 \mathrm{kN}$. The first $3 \mathrm{D}$ printed model was on show at Aero India expo-2015 as an operating platform.

\section{APPLICATION OF AM IN AEROSPACE}

AM has a wide scope in the aerospace application. It is a technology that differs from traditional and subtractive manufacturing in terms of lightweight, improved performance, increased fuel economy, increased system efficiency, etc. The keyword additive denotes the making style of a printer that is a layer over a layer rather than removing it from raw material. The weight, fuel economy, and system efficiency matter a lot for aerospace applications. Aerospace AM is on the verge of taking off (Figure 3), with market dynamics and growing technical sophistication allowing AM to be taken up further [29].

In terms of fuel consumption, if we consider at the expense of holding an entity airborne or sending a rocket into orbit, the lighter parts make more difference. Undoubtedly, if the component is light, it will have better fuel consumption, or improve system performance. The ultimate goal of this is to reduce the weight of parts by AM. For geostationary orbit, the payload on it runs over thousands of kilograms. In such cases, this light-weighting of components can help to reduce the fuel economy. In civil aviation, every kilogram carried cost hundreds of dollars per year, per aircraft, an airline, or a rocket. 
If we add the weight and cost through the aircraft fleet, the overall expanse is immense. There are unknown possibilities for light weighting in the airplane region. In an aircraft cabin, think about all non-structural, non-light essential metal elements. Instead of solid, these components can be made hollow to lighten the part by rendering its internal lattice structure to minimize weight without compromising its usability. Metal 3D printing provides hundreds of possibilities to extract mass and save fuel economy.

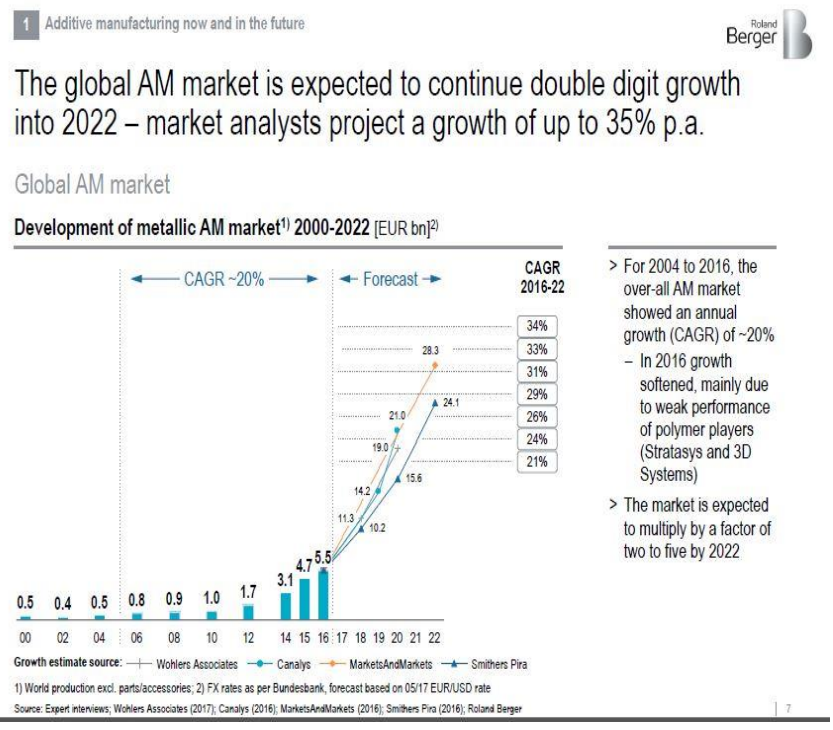

Figure 3. AM global market analysis [30]

\subsection{D printed communication satellite}

If this technology is used properly, it can have beneficial effects on machine performance. As the parts are made with 3D printing its weight will be less so ultimately it impacts on fuel consumption rate. The more the weight the more will be the fuel required to carry the same. These two areas are directly dependent on each other. Removing weight from parts or assembly with the design and production process makes a positive impact and leads to impressive system benefits. For example, reducing weight on the reflectors of communication satellite (Figure 4 \& 5) reduces the fuel economy and ultimately saves the cost with the same performance may be improved with additive manufacturing.

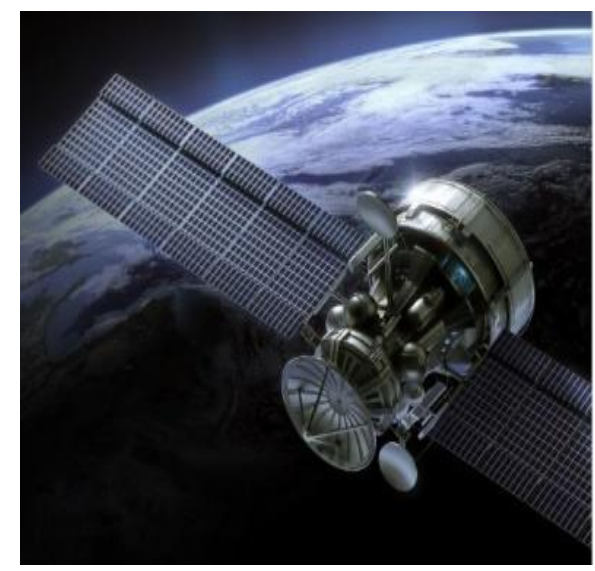

Figure 4. Bracket made by AM to reduce the weight for communication satellite [31]

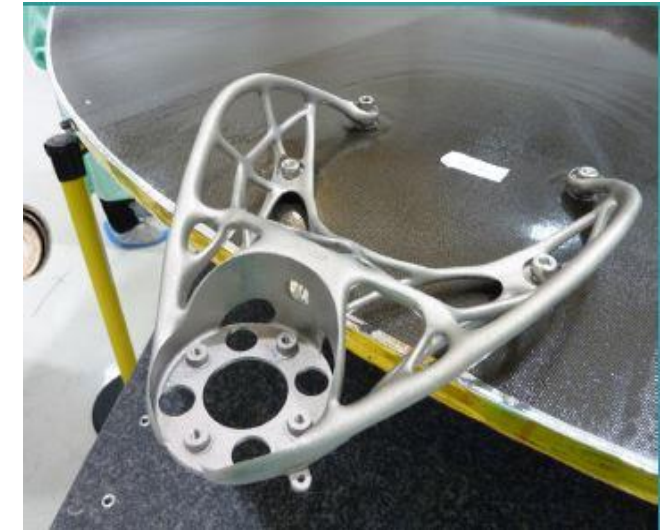

Figure 5. Satellite orbiting earth which can be lighten in terms of weight [31]

\subsection{Radio frequency filters}

Waveguides and regulators for the metal radio frequency (Figure 6) are vital components of a telecommunication satellite. They behave like traffic cops to permit the movement of signals and inform signals to go around. A satellite high via placed will bring hundreds of these filters onto it to communicate. Trying to find ways to reduce its weight and speed up production, Airbus Defence and Space has been exploring 3D metal printing. Consequently, the first 3D printed RF filters to be tested and approved for use in communication satellites were accomplished. Compared to previous models, the new filters have decreased weight by 50 percent and designed as a single component instead of making assembly of different parts. The 3D printed RF filters were rigorously tested and each met its specified requirement, making technology an important tool in terms of weight loss, cost reduction, and improvement of production time.

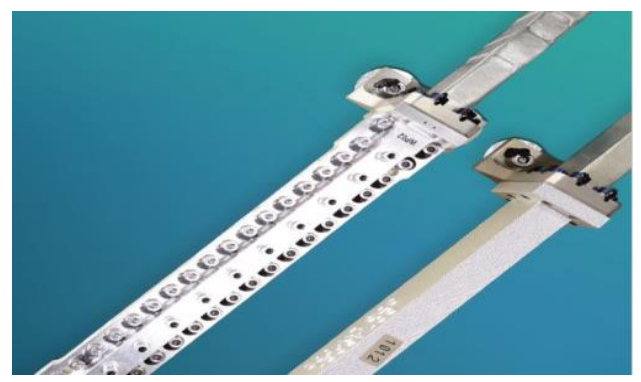

Figure 6. 3D printed RF filters for communication satellite [31]

\subsection{Satellite bracket}

Satellite brackets are fabricated by AM technology to reduce its weight and to increase the fuel economy. These skeleton liked brackets are 3D printed with titanium (Figure 7) and optimized by topological optimization. To satisfy the output criteria of the bracket, it is decided the most effective arrangement of material. Such titanium-based brackets are 25 percent lighter than commonly produced methods and give improved weight ratio stiffness. Metal 3D printing and digital modeling provide the exclusive produced edition. These are customized and designed to satisfy their particular position and produced in half the time. In the aerospace industry, 3D metal printing has made some major significant advances over the last year. Companies like General Electric and government 
agencies like NASA have invested in designing and creating new 3D-printed alloys to withstand high-speed, high-heat conditions while improving the engine's power-to-weight ratio.AM can minimize scrap metal by up to 90 percent compared to conventional manufacturing methods to improve material costs.

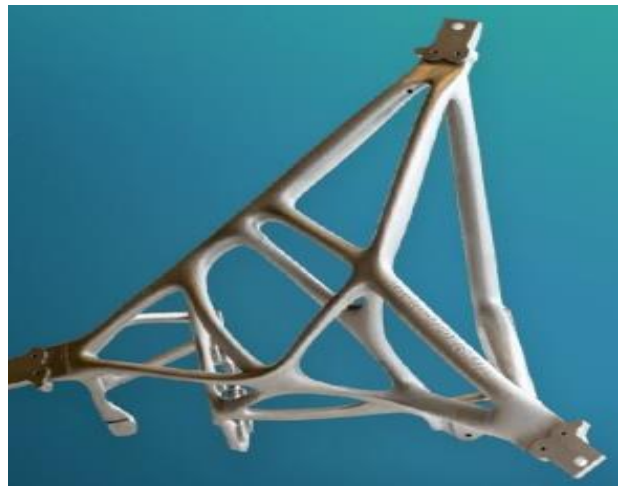

Figure 7. 3D printed titanium bracket [32]

\subsection{Rocket engine for spaceship fabricated by 3D printer}

3D printing offers versatility in complex design as a single part. When it relates to the engine it is an assembly of series of small parts for a spacecraft. But can one imagine it as a single part manufactured in a single stroke? As a single part, you can integrate integral cooling channels into a combustion chamber as a single all in one design. The US-based company named LAUNCHER (Figure 8) is working on small to medium scale payloads into space by printing a rocket as a single part with $3 \mathrm{D}$ printing. This 3D printed rocket is based on standard design but it is extended with an internal cooling system supported with ribs. This company is successfully printed and successfully tested. With these results, it gave a hope to design new innovative design considering cost-effectiveness by lightweighting.

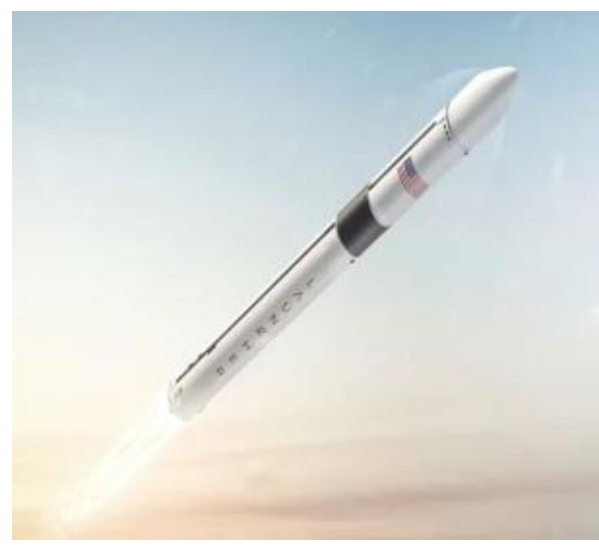

Figure 8. 3D printed rocket [33]

\subsection{Combustion chamber printed by 3D printer}

With 3D printing technology, the combustion chamber of the M4K machine is built successfully by AMCM Company. It is the largest single piece combustion chamber (Figure 9) for liquid rocket engine in the world. It is made of copper alloys and developed with the EOS system.

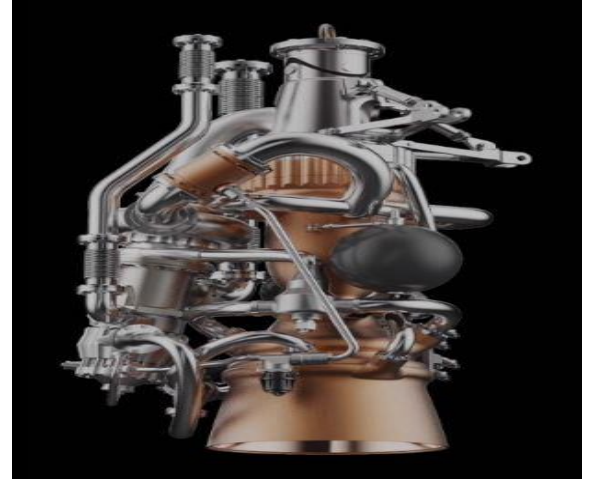

Figure 9. 3D printed liquid rocket engine [33]

\subsection{D printed nozzle (injector heads)}

The Ariane 6 Rocket engine is built with 3D printing technology. By use of additive manufacturing the plan was to reduce down the number of parts for system efficiency. This is having injector heads with number and 3D printed. This integration multiple nozzles as shown in Figure 10 with traditional machining were difficult but it was never with 3D printing. The successfully printing of these injector heads with fuel economy was achieved. This is an integration of injector nozzles with cost benefit of more than $50 \%$ and lead time reduction with three times as compared with traditional manufacturing process. This injector head is having 1800 holes and takes months with conventional process but with $3 \mathrm{D}$ printing it just takes 35 hours. This is the advantage of this technology giving the new edge to manufacturing process.

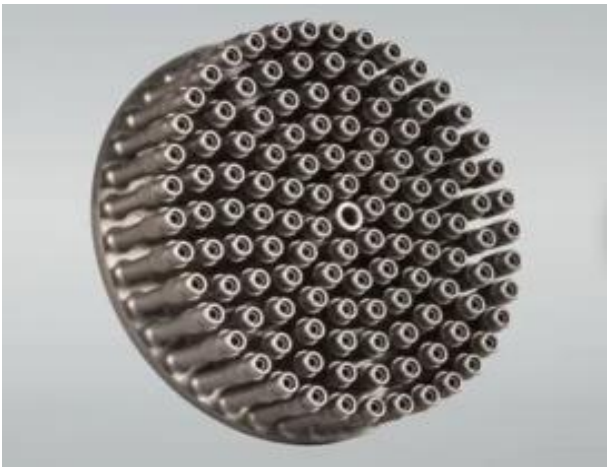

Figure 10. 3D printed injector heads [33]

\section{ISSUES TO BE ADDRESSED: CHALLENGES}

- $\quad \mathrm{AM}$ is used for a variety of applications and operated under different circumstances. Multifunctional frameworks are simple to obtain via the massive geometric freedom provided by AM technologies and have several possible advantages for the aerospace industry. Changes are required to fulfill the everincreasing functionalities in their physical shape, height, weight, power, and resilience. The reason for using AM is to come up with a solution that can satisfy the needs of the final consumer. The following are some of the issues as challenges observed:

- Material is the most deciding factor to reduce the final weight of the components and their reliability. Metal powder analysis for the aerospace industry includes measuring the average powder size, powder 
size distribution, surface area, flowability, observable density, humidity, and product porosity are the common factors. For several cases, these details are appropriate needed by the end consumer [34].

- The printed part's intrinsic anisotropic property is another AM disadvantage. The presence of this defect changes the microstructure tends to be expanding in some direction. It affects the mechanical properties. The manufacturing staircase perspective leads to induced porosity in the manufactured component of improper densification [35].

- Inadequate information on the properties of AM materials can lead to incorrect assessment of strength and material application.

- $3 \mathrm{D}$ printing is applicable for small components whereas, aircraft application required large components which slow down the progress of this technology.

- Certification of quality products and their assurance is an essential step before promoting the final AM manufactured part into the market.

- AM materials production costs are higher than the conventional methods because it needs the required processes to turn the content of material into the correct forms for AM operations.

\section{DISCUSSION}

$\mathrm{AM}$ is revolutionizing the manufacturing process through the ability to print complex geometries, reduce lead time, and flexibility. Generally, traditional manufacturing like casting, welding, and forging processes are applied to make the aerospace components results in a lot of wastages and time consuming. Although, the mechanical strength of these fabricated components is higher than the AM manufactured parts. AM has become the most researched area for the aerospace industry due to making complicated, high temperature, and consolidates components. Many researchers are working on the challenges part associated with the AM process. There is a need for proper quality assurance and standardization of AM fabricated components before considered for application. ASTM F-42 community, SAE, and the ISO TC 261 are working on the qualification and certification methods, design guidelines, test methods for characteristics of raw materials, material recycling guidelines, etc. More study is needed between the pre-processing, in-situ control and the post-processing phase to analyze the shape deviation, the physical phenomenon of the melt pool, and optimize the process parameters. More systematic work is needed to achieve a broader use of the technology. Before this, the following important aspects need specific research attention:

- Closer assessment of AM processes physics and evaluation of powder characterization.

- Proper understanding of failure mechanism and material irregularities.

- Need to develop a correlation between the material property and manufactured part.

- AM component design guidelines and rulemaking.

- Assess the real-time behavior of melt pool and products to analyze the mechanical properties.

- $\quad$ Proper monitoring and testing of AM parts.
- Part quality can be enhanced by using postprocessing steps like hot isostatic process, heat treatments.

- Certification and qualification of AM parts and processes are paramount and needs to be accelerated.

\section{CONCLUSIONS}

Additive manufacturing methods have attracted their interest in aerospace components manufacturing. AM gives engineers versatility in manufacturing complex patterns that are difficult to produce using traditional techniques.

- Molding and tooling are not required for AM techniques, therefore saving time, cost, and energy. This study explores the advancement of AM techniques used by various parts of the economy.

- Addresses in detail how AM methods in different industries can increase structural and aerodynamic performance. For all of AM's benefits, it still struggles from the constraints which need addressing.

- Lack of quality-strength materials, lack of diagnostic methods, anisotropic properties, and low build volumes identify the potential of AM to become a viable business solution.

- Additionally, ongoing advancement and development in additive manufacturing would be a remarkable place in the future of aerospace production.

\section{REFERENCES}

[1] Kobryn, P.A., Ontko, N.R., Perkins, L.P., Tiley, J.S. (2006). Additive manufacturing of aerospace alloys for aircraft structures. Air Force Research Lab WrightPatterson AFB OH Materials and Manufacturing Directorate.

[2] Chen, L., He, Y., Yang, Y., Niu, S., Ren, H. (2017). The research status and development trend of additive manufacturing technology. The International Journal of Advanced Manufacturing Technology, 89(9-12): 36513660. https://doi.org/10.1007\%2Fs00170-016-9335-4

[3] Monzón, M.D., Ortega, Z., Martínez, A., Ortega, F. (2015). Standardization in additive manufacturing: activities carried out by international organizations and projects. Int. J. Adv. Manuf. Technol., 76: 1111-1121. https://doi.org/10.1007\%2Fs00170-014-6334-1

[4] Liu, R., Wang, Z., Sparks, T., Liou, F., Newkirk, J. (2017). Aerospace applications of laser additive manufacturing. In Laser additive manufacturing. Woodhead Publishing, 351-371. https://doi.org/10.1016/B978-0-08-100433-3.00013-0

[5] Shu, X., Chen, G., Liu, J., Zhang, B., Feng, J. (2018). Microstructure evolution of copper/steel gradient deposition prepared using electron beam freeform fabrication. Materials Letters, 213: 374-377. https://doi.org/10.1016/j.matlet.2017.11.016

[6] Sutton, A.T., Kriewall, C.S., Leu, M.C., Newkirk, J.W. (2017). Powder characterization techniques and effects of powder characteristics on part properties in powderbed fusion processes. Virtual Phys Prototyp, 12: 3-29. https://doi.org/10.1080/17452759.2016.1250605 
[7] Seabra, M., Azevedo, J., Araújo, A., Reis, L., Pinto, E., Alves, N., Mortágua, J.P. (2016). Selective laser melting (SLM) and topology optimization for lighter aerospace componentes. Procedia Structural Integrity, 1: 289-296. https://doi.org/10.1016/j.prostr.2016.02.039

[8] Brenken, B., Barocio, E., Favaloro, A., Kunc, V., Pipes, R.B. (2018). Fused filament fabrication of fiberreinforced polymers: A review. Additive Manufacturing, 21: 1-16. https://doi.org/10.1016/j.addma.2018.01.002

[9] Živanović, S.T., Popović, M.D., Vorkapić, N.M., Pjević, M.D., Slavković, N.R. (2020). An overview of rapid prototyping technologies using subtractive, additive and formative processes. FME Transactions, 48(1): 246-253.

[10] Pavlović, A., Šljivić, M., Kraisnik, M., Ilić, J., Anić, J. (2017). Polymers in additive manufacturing: The case of a water pump impeller. FME Transactions, 45(3): 354359.

[11] Wohlers, T. (2010). Additive Manufacturing State of the Industry, Wohlers report, Wohlers Associates, Inc.

[12] https://www.3dnatives.com/en/additive-manufacturingaerospace-growing-061220184/.

[13] ISO/ASTM 52900: 2015 (E). (2016). Standard Terminology for Additive Manufacturing-General Principles-Terminology.

[14] Wohlers, T. (2018). Wohlers Report 2018. Wohlers Associates, Inc.

[15] Concept Laser. Laser melting with metals in aircraft manufacturing 3D printing enables "bionic" aircraft designs. Available from: http://www.conceptlaserinc.com/portfolioitems/lasermelting-metals-aircraft-manufacturing-2/\#prettyPhoto last accessed 2020/4/30.

[16] https://www.airbus.com/public-affairs/brussels/ourtopics/innovation/3d-printing.html, accessed on 2020/4/30.

[17] https://www.3dhubs.com/knowledge-base/aerospace3d-printing-applications/, accessed on 2020/4/30.

[18] Kellner, T. (2014). Fit to print: new plant will assemble world's first passenger jet engine with 3D printed fuel nozzles, next-gen materials. General Electric, Boston, MA, accessed on Nov, 29, 2016.

[19] Kellner, T. (2015). The FAA cleared the first 3D printed part to fly in a commercial jet engine from GE. 2015.

[20] https://3dprintingindustry.com/news/premium-aerotecpartners-with-lockheed-martin-to-integrate-additivemanufacturing-into-f-35-aircraft-157977/, accessed on 2020/5/1.

[21] https://3dprintingindustry.com/news/lockheed-martinshares-its-5-ps-for-industrial-3d-printing-136902/, accessed on 2020/5/2.

[22] https://www.machinedesign.com/3d-printing$\mathrm{cad} / \mathrm{media}$-gallery/21835191/metal-3d-printing-toshape-the-aerospace-industry, accessed on 2020/5/2

[23] https://www.eos.info/en/3d-printing-examplesapplications/aerospace-3d-printing/space-propulsionsatellites, accessed on 2020/5/2.

[24] Anderson, S. (2015). Rolls-Royce to get largest 3D printed component off the ground, flight-testing engine later Year, Feb (2015).

[25] https://digital.hbs.edu/platformrctom/submission/additiv e-manufacturing-revolutionizes-aerospace/, accessed on 2020/5/3

[26] https://economictimes.indiatimes.com/news/science/indi a-is-slowly-catching-up-with-the-world-to-use-3dprinting-in-building-products/articleshow/67085613, accessed on 2020/5/3.

[27] https://3dprintingindustry.com/news/accreate-labs-to3d-print-user-interface-panels-for-the-isro-spaceproject-149874/, accessed on 2020/5/2.

[28] RAPITECH Solutions Inc., Project Engine Prototype Model. RAPITECH Solutions Inc., India.

[29] https://www.rolandberger.com/en/Publications/Aerospa ce-suppliers-brace-for-headwinds.html, accessed on 2020/5/1

[30] Easter S., Turman J., Sheffler D., Balazs M. (2013). Using advanced manufacturing to produce unmanned aerial vehicles: a feasibility study. SPIE Defense, Security, and Sensing: 874204-874216.

[31] https://www.3dsystems.com/sites/default/files/201906/3DSystems-eBook-MetalLightweighting_NewStyle_AW\%20\%283\%29.pdf, Ebook for metal additive manufacturing last accessed 2020/5/2.

[32] https://www.machinedesign.com/3d-printingcad/media-gallery/21835191/metal-3d-printing-toshape-the-aerospace-industry, last accessed 2020/5/1.

[33] https://www.eos.info/en/3d-printing-examplesapplications/aerospace-3d-printing/space-propulsionsatellites, last accessed 2020/5/1.

[34] Vrancken, B., Thijs, L., Kruth, J.P., Van Humbeeck, J. (2012). Heat treatment of Ti6Al4V produced by Selective Laser Melting: Microstructure and mechanical properties. Journal of Alloys and Compounds, 541: 177185. https://doi.org/10.1016/j.jallcom.2012.07.022

[35] ASTM Standard F3003-14(2014). Standard Specification for Quality Assurance of a Small Unmanned Aircraft System (UAS), ed. West Conshohocken, PA: ASTM International. 